\title{
Article \\ Multispectral Imaging Algorithm Predicts Breslow Thickness of Melanoma
}

\author{
Szabolcs Bozsányi ${ }^{1,2}{ }^{\mathbb{D}}$, Noémi Nóra Varga ${ }^{1}$, Klára Farkas ${ }^{1} \mathbb{D}$, András Bánvölgyi ${ }^{1}$, Kende Lórincz ${ }^{1} \mathbb{D}$,

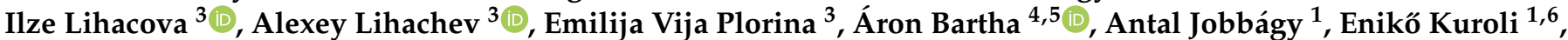 \\ György Paragh ${ }^{7,8} \mathbb{D}^{\mathbb{D}}$, Péter Holló ${ }^{1}$, Márta Medvecz ${ }^{1} \mathbb{D}$, Norbert Kiss ${ }^{1,+} \mathbb{D}$ and Norbert M. Wikonkál ${ }^{1, *,+}$
}

Citation: Bozsányi, S.; Varga, N.N.; Farkas, K.; Bánvölgyi, A.; Lőrincz, K. Lihacova, I.; Lihachev, A.; Plorina, E.V.; Bartha, Á.; Jobbágy, A.; et al. Multispectral Imaging Algorithm Predicts Breslow Thickness of Melanoma. J. Clin. Med. 2022, 11, 189 https://doi.org/10.3390/jcm11010189 Academic Editor: Masutaka Furue

Received: 5 December 2021

Accepted: 26 December 2021

Published: 30 December 2021

Publisher's Note: MDPI stays neutral with regard to jurisdictional claims in published maps and institutional affiliations.

Copyright: (C) 2021 by the authors. Licensee MDPI, Basel, Switzerland. This article is an open access article distributed under the terms and conditions of the Creative Commons Attribution (CC BY) license (https:// creativecommons.org/licenses/by/ $4.0 /)$.
1 Department of Dermatology, Venereology and Dermatooncology, Semmelweis University, 1085 Budapest, Hungary; bozsanyi.szabolcs@med.semmelweis-univ.hu (S.B.); varga.noemi@stud.semmelweis.hu (N.N.V.); farkas.klara@phd.semmelweis.hu (K.F.); banvolgyi.andras@med.semmelweis-univ.hu (A.B.); lorincz.kende@med.semmelweis-univ.hu (K.L.); antaljobbagy@gmail.com (A.J.); kuroli.eniko@med.semmelweis-univ.hu (E.K.); hollo.peter@med.semmelweis-univ.hu (P.H.); medvecz.marta@med.semmelweis-univ.hu (M.M.); kiss.norbert@med.semmelweis-univ.hu (N.K.)

2 Selye János Doctoral College for Advanced Studies, Clinical Sciences Research Group, 1085 Budapest, Hungary

3 Biophotonics Laboratory, Institute of Atomic Physics and Spectroscopy, University of Latvia, 1004 Riga, Latvia; ilze.lihacova@lu.lv (I.L.); aleksejs.lihacovs@lu.lv (A.L.); emilija_vija.plorina@lu.lv (E.V.P.)

4 Department of Bioinformatics, Semmelweis University, 1085 Budapest, Hungary; bartha.aron@med.semmelweis-univ.hu

5 2nd Department of Pediatrics, Semmelweis University, 1085 Budapest, Hungary

6 1st Department of Pathology and Experimental Cancer Research, Semmelweis University, 1085 Budapest, Hungary

7 Department of Dermatology, Roswell Park Comprehensive Cancer Center, Buffalo, NY 14203, USA; gyorgy.paragh@roswellpark.org

8 Department of Cell Stress Biology, Roswell Park Comprehensive Cancer Center, Buffalo, NY 14203, USA

* Correspondence: wikonkal.norbert@med.semmelweis-univ.hu

+ These authors contributed equally to this work.

Abstract: Breslow thickness is a major prognostic factor for melanoma. It is based on histopathological evaluation, and thus it is not available to aid clinical decision making at the time of the initial melanoma diagnosis. In this work, we assessed the efficacy of multispectral imaging (MSI) to predict Breslow thickness and developed a classification algorithm to determine optimal safety margins of the melanoma excision. First, we excluded nevi from the analysis with a novel quantitative parameter. Parameter s' could differentiate nevi from melanomas with a sensitivity of $89.60 \%$ and specificity of $88.11 \%$. Following this step, we have categorized melanomas into three different subgroups based on Breslow thickness ( $\leq 1 \mathrm{~mm}, 1-2 \mathrm{~mm}$ and $>2 \mathrm{~mm}$ ) with a sensitivity of $78.00 \%$ and specificity of $89.00 \%$ and a substantial agreement $(K=0.67 ; 95 \% \mathrm{CI}, 0.58-0.76)$. We compared our results to the performance of dermatologists and dermatology residents who assessed dermoscopic and clinical images of these melanomas, and reached a sensitivity of $60.38 \%$ and specificity of $80.86 \%$ with a moderate agreement $(k=0.41 ; 95 \% \mathrm{CI}, 0.39-0.43)$. Based on our findings, this novel method may help predict the appropriate safety margins for curative melanoma excision.

Keywords: melanoma; surgery; Breslow thickness; LED; dermoscopy; quantitative analysis; melanin; multispectral imaging; histology; diagnosis

\section{Introduction}

Melanoma is a malignant melanocytic tumor that accounts for the majority of the skin cancer-related mortality [1-3]. Approximately 232,100 new invasive melanomas are diagnosed worldwide, and melanoma accounts for more than 55,000 deaths annually [4] Melanoma has four main subtypes: (1) superficial spreading melanoma (SSM), (2) nodular melanoma (NM), (3) lentigo maligna melanoma (LMM), and (4) acral lentiginous melanoma 
(ALM) [5]. According to the American Academy of Dermatology, the National Institute of Health, and the National Comprehensive Cancer Network, surgical excision followed by histopathological evaluation is the gold standard for diagnosing melanoma $[6,7]$. The Breslow tumor thickness is the maximum perpendicular invasion of the tumor, the distance in millimeters between the granular layer of the dermis or the base of ulceration, and the deepest point invaded by tumor cells $[6,8]$ not including deeper follicular or adventitial extension [6]. The presumed or confirmed tumor depth is a vital element of the tumor staging [9], which defines the required surgical safety margin [10]. If histology finds thicker melanoma than clinically expected and the melanoma excision had insufficient surgical margins, reoperation is needed. Breslow thickness is the strongest predictor of metastatic spread [11] and determines the need for sentinel lymph node biopsy (SLNB). SLNB is required if Breslow thickness is more than $0.8 \mathrm{~mm}$ [12].

Non-invasive optical imaging modalities have great potential in melanoma diagnosis and the estimation of tumor depth. Dermoscopy is the most widely used skin imaging tool in dermatology. Among various other applications, it has also been applied to predict Breslow thickness [13]. Specific dermoscopic patterns can be helpful in predicting thickness. Light brown color, atypical pigment network, regression, and hypopigmented areas are typically present in thin melanomas. In contrast, thick melanomas are associated with blue-white veil, milky red areas, blue-black pigmentation, irregular vessels, shiny white streaks, rainbow pattern, ulceration, and pseudolacunae [14].

Various non-invasive imaging methods have been used to assess melanoma thickness, such as high-frequency ultrasound (HFUS) [15] and photoacoustic microscopy [16]. Optical coherence tomography (OCT) is a potent tool to diagnose melanoma in vivo based on the structural and visual characteristics [17] and can predict the depth of thin melanomas $(<400 \mathrm{~mm})$ [18]. HFUS was more suitable to measure the thickness of deeper lesions $(>400$ $\mathrm{mm})$ [18]. Reflectance confocal microscopy (RCM) is a non-invasive imaging modality which can differentiate melanomas from other skin lesions based on their visible and characteristic patterns in vivo [19] and ex vivo [20]. RCM could classify melanomas into thick $(>1 \mathrm{~mm})$ and thin $(\leq 1 \mathrm{~mm})$ subgroups in vivo [21]. Another confocal microscopy modality, confocal laser scanning microscopy, proved to be a promising tool to estimate preoperative tumor thickness also, and its ex vivo results correlated with the histological findings [22]. These non-invasive imaging techniques are capable of providing a diagnosis of melanoma and estimate its depth, but their prices are high and their use requires special training and expertise.

Multispectral imaging (MSI) is an emerging diagnostic technique $[23,24]$ that uses different wavelength bands to capture images [25] mostly between the visible and infrared light spectrum (400-970 nm) provided by light bulbs or LED lights [26]. This method combines the advantages of spectrophotometry (spectral resolution) and digital cameras (spatial resolution) [23]. MSI has been used formerly to distant map skin chromophores, such as hemoglobin and melanin [27]. The primary advantage of MSI compared to other imaging modalities is its cost-effectiveness and that it can also be implemented into smartphone cameras [28,29]. Recently, MSI was also used to detect skin cancer recurrence [30,31]. MSI can also differentiate benign lesions from malignant tumors based on their autofluorescence intensity (AF) [32]. Our research group has previously shown this technique to differentiate seborrheic keratosis from melanoma [33]. In addition, we introduced MSI for the diagnostics of rare skin disorders, including pseudoxanthoma elasticum [34] and keratinopathic ichthyosis [35].

In our present study, we aimed to develop and assess a novel MSI algorithm for melanoma Breslow tumor thickness prediction, and thus the determination of optimal safety margins of melanoma surgeries. Then we compared the algorithm to the performance of clinical assessment by dermatologists and dermatology residents. 


\section{Materials and Methods}

\subsection{Inclusion Criteria}

In this study we included primary cutaneous melanomas histologically verified by expert dermatopathologists, and nevi confirmed by two expert dermatologists with clinical and dermoscopic examination. Only lesions on body parts accessible to the MSI device were investigated. If the lesion was larger than the field of view, multiple image sets were captured.

\subsection{Exclusion Criteria}

We excluded cases where histopathological report was not available, cases that proved to be melanoma metastases, as well as primary melanomas of special sites (acral, genital, or mucosal melanoma), and melanomas with tumor thickness higher than $10 \mathrm{~mm}$. Thick hair density, bleeding, or scales that impeded an adequate dermoscopic evaluation were also excluded. In situ melanomas were also excluded from this study.

\subsection{Multispectral Imaging and Analysis of Intensity Values and Shape Descriptors}

MSI was performed at the Department of Dermatology, Venereology and Dermatooncology, Semmelweis University (Budapest, Hungary) and at the Oncology Center of Latvia (Riga, Latvia). The handheld prototype used in this study was developed by the University of Latvia in collaboration with Riga Technical University (Riga, Latvia). The illumination source was an LED ring which contained four types of LED-diodes with wavelengths of $405 \mathrm{~nm}$ (autofluorescence/AF), $525 \mathrm{~nm}$ (green/G), $660 \mathrm{~nm}$ (red/R), and $940 \mathrm{~nm}$ (infrared/IR), penetrating to different layers of skin with irradiating power density of $20 \mathrm{~mW} / \mathrm{cm}^{2}$ and field of view of $2 \times 2 \mathrm{~cm}^{2}$. We used the $\mathrm{G}, \mathrm{R}$, and IR channels for the quantitative analyses. This device was designed to measure skin diffuse reflectance images by using these four different LED illuminations fixed at $35 \mathrm{~mm}$ distance, arranged circularly in the ring and covered by a matt plate diffusor to deliver uniform illumination. Images were collected with a color CMOS 5-megapixel IDS camera (MT9P006STC, IDS uEye UI3581LE-C-HQ, Obersulm, Germany) fixed at $60 \mathrm{~mm}$ distance from the illuminated skin [36]. The acquired images were automatically transferred to a cloud server for further data processing and analysis [37]. A long-pass filter (T515 nm > 90\%) was inserted in front of the camera, allowing it to capture G, R, and IR spectral channels. The detailed description of this prototype device has been previously published [36,38]. The LED-based multispectral images were analyzed with ImageJ v1.46 software (NIH, Bethesda, MD, USA) [39]. For the intensity analysis and shape description, we manually selected the regions of interests (ROI) using freehand selections. ROIs of melanomas were recorded using the ROI manager function of the ImageJ software. Therefore, the analyzed area was identical in all channels (G, R, IR). We measured the mean gray value (integrated density/area), circularity ( $4 \pi$ area/ perimeter $^{2}$ ), solidity (area/convex area), and roundness $\left(4 \times\right.$ area $/\left(\pi \times\right.$ major_axis $\left.\left.{ }^{2}\right)\right)$.

\subsection{Differentiation of Nevi from Melanomas with the Use of Parameter s'}

We used a novel parameter to exclude nevi as the first step of the melanoma classification algorithm. Parameter $s^{\prime}$ is based on our previous studies [40-43].

$$
\text { parameter } s^{\prime}=\lg \frac{I_{G} \cdot I_{R}^{2} \text { skin }}{I_{G_{\_} s k i n} \cdot I_{R}^{2}}
$$

where $I_{G}$ : intensity of lesion in green channel,

$I_{G-s k i n}:$ mean intensity of skin in green channel,

$I_{R}$ : intensity of lesion in red channel,

$I_{R \_s k i n}:$ mean intensity of skin in red channel.

We used the patient data of the melanoma patients mentioned before from which 98 patients met the requirement of the parameter s' assessment (126 image sets). The ac- 
quired images were automatically transferred to a cloud server for further data processing and analysis [37]. The image processing algorithms were developed in Matlab (MathWorks) [41]. We used the patient data of the Department of Dermatology, Venereology and Dermatooncology, Semmelweis University (Budapest, Hungary) and the Oncology Center of Latvia (Riga, Latvia), including 143 nevi.

\subsection{Melanoma Classification Algorithm}

We developed an algorithm to classify melanomas into three subgroups (Breslow tumor thickness $\leq 1 \mathrm{~mm}$, Breslow tumor thickness 1-2 mm, and Breslow tumor thickness $>2 \mathrm{~mm}$ ) based on the shape descriptors and intensity values of their MSI images. As a first step, this method confirms melanomas and rules out nevi from the calculation. This is followed by the second step where the algorithm carries out the thresholding between low and high circularity (threshold: 0.727; arbitrary unit, A.U.) The next step is the intensity analysis of these two subgroups. Melanomas with low circularity go through an intensity measurement of the $\mathrm{G}$ channel (threshold: 8.0 A.U.). Melanomas with a higher $\mathrm{G}$ intensity are classified as melanomas with Breslow $\leq 1 \mathrm{~mm}$, and melanomas with lower $\mathrm{G}$ intensity are classified as tumors with Breslow 1-2 mm. The IR channel was analyzed for melanomas with low circularity. Melanomas with lower intensities (threshold 107.9 A.U.) were classified as Breslow $>2 \mathrm{~mm}$ and melanomas with higher IR intensities were classified as Breslow 1-2 mm.

\subsection{Dermoscopic Image Analysis by Dermatologists and Dermatology Residents}

A spreadsheet-based evaluation form was sent to the dermatologists and dermatology residents of the Department of Dermatology, Venereology and Dermatooncology. This spreadsheet contained dermoscopic images of the 100 investigated melanomas (one to three), a clinical image of the melanomas, and the answers included for the three subgroups (Breslow $\leq 1 \mathrm{~mm}$, Breslow 1-2 mm, Breslow $>2 \mathrm{~mm}$ ).

\subsection{Statistical Analysis}

One-way ANOVA was used for statistical analysis to compare the intensity values and shape descriptors. We used receiver operating characteristic (ROC) curves to count the area under the curves (AUC) with default settings (Wilson/Brown method with a confidence interval of $95 \%$ ). We used Pearson correlation to correlate intensity values with Breslow thickness. Cohen's kappa ( $\mathrm{\kappa}$ ) was used to calculate concordance. Statistical tests were performed using GraphPad Prism v8.0.1. software (GraphPad Software Inc., La Jolla, CA, USA) and $R$ version 3.6.1. $p$ values below 0.05 were considered statistically significant. The results are expressed as mean \pm standard error.

\section{Results}

\subsection{Patient Data and Histology}

In this study, we examined 100 patients with primary melanoma. In total, 128 image sets were collected. Of the 100 melanomas, 69 were SSM (69\%), 19 NM (19\%), 2 ALM (2\%), 3 LMM (3\%), 1 naevoid (1\%), and 6 unclassified (6\%). The mean age of affected patients was $62.64 \pm 14.29$ years. The sex ratio was $37 \%$ women and $63 \%$ men. The mean Breslow thickness was $1.777 \pm 1.728 \mathrm{~mm}$, ranging from $0.12 \mathrm{~mm}$ to $7.5 \mathrm{~mm}$ (Figure 1). 

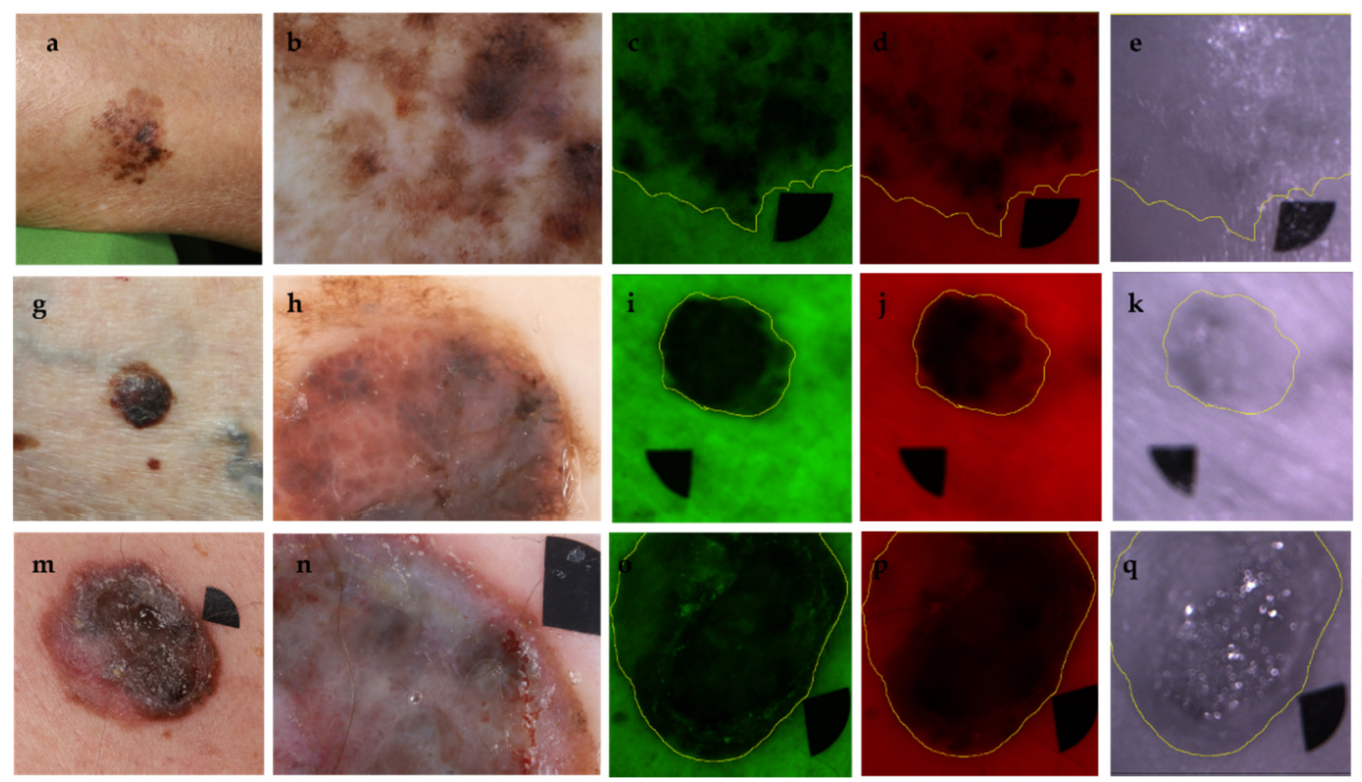

f
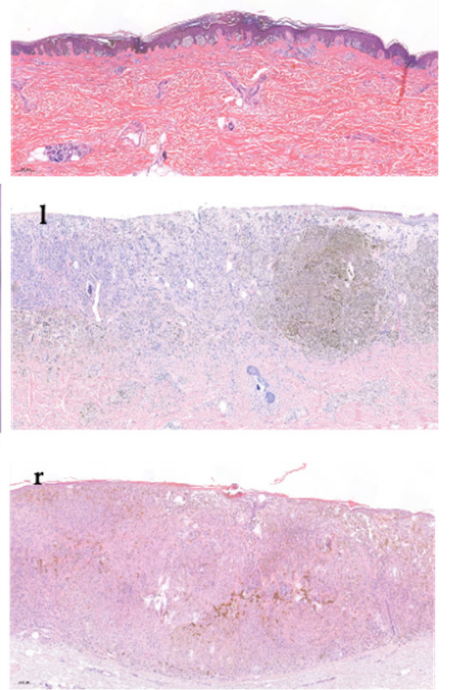

Figure 1. Representative images of melanomas with different Breslow thicknesses. Upper row (a-f); melanoma with Breslow $0.345 \mathrm{~mm}$, pT1a, Clark II, superficial spreading melanoma (SSM), clinical photograph (a), dermoscopic image (b), G (c), R (d), and IR (e) channels and histological image (f). Middle row (g-l); melanoma with Breslow $1.81 \mathrm{~mm}$, pT2a, Clark IV, SSM, clinical photograph (g), dermoscopic image (h), G (i), R (j), and IR (k) channel, histological image (1). Lower row (m-r); melanoma with Breslow $2.42 \mathrm{~mm}$, pT3b, Clark IV, SSM with a nodular component, clinical photograph $(\mathbf{m})$, dermoscopic image (n), G (o), R (p), and IR (q) channels and histological image (r). Black markers (area: $\left.0.125 \mathrm{~cm}^{2}\right)$ are used for image alignment. Histology magnification $51 \times(\mathbf{f})$ and $50 \times(\mathbf{l}, \mathbf{r})(\mathrm{H} \& \mathrm{E}$ staining).

\subsection{Intensity Values}

When the intensity values of various melanomas were studied, we found significant differences in the green $(\mathrm{G})$ and red $(\mathrm{R})$ MSI channels that allowed us to efficiently differentiate the Breslow $\leq 1 \mathrm{~mm}$ group from the other two groups. In these tumors, the intensity measured in these channels of Breslow $\leq 1 \mathrm{~mm}$ melanomas were significantly higher than in the other two subgroups. Readouts in the infrared (IR) channel did not provide valuable information to distinguish between thinner or thicker, more invasive melanomas. The strongest correlation was between IR intensity and Breslow thickness ( $\mathrm{r}$ : $-0.6593, p$ value: $<0.0001,95 \%$ confidence interval: -0.7576 to -0.5317$)$, whereas the $G$ and $\mathrm{R}$ channels displayed a lower correlation with tumor thickness (Figure 2).

\subsection{Shape Descriptors}

Among the shape descriptors, both circularity and solidity proved significantly lower in the Breslow $\leq 1 \mathrm{~mm}$ group than in the other two subgroups. Investigations of the circularity and solidity made it possible to distinguish the Breslow 1-2 $\mathrm{mm}$ and the Breslow $>2 \mathrm{~mm}$ subgroups. This was based on the fact that Breslow $>2 \mathrm{~mm}$ melanomas had significantly higher circularity and solidity values. However, the roundness did not show any significant differences. Circularity $(p:<0.0001)$ and solidity $(p:<0.0001)$ proved to be efficient in differentiating thick or nodular melanomas from thin melanomas. Pearson's correlation showed a high correlation between solidity ( $\mathrm{r}$ : $0.6324,95 \%$ confidence interval: 0.4978 to $0.7372, p$ : $<0.0001$ ) and between circularity and Breslow thickness (r: $0.710995 \%$ confidence interval: 0.5980 to $0.7961, p:<0.0001$ ), whereas the roundness showed no significant differences between the three subgroups ( $p$ value $=0.2139$ ). 
a

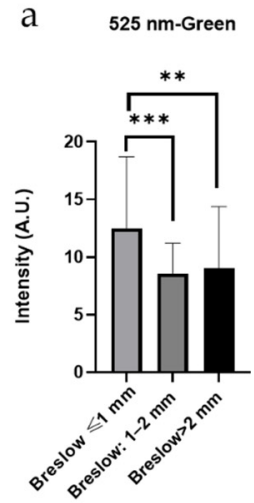

d

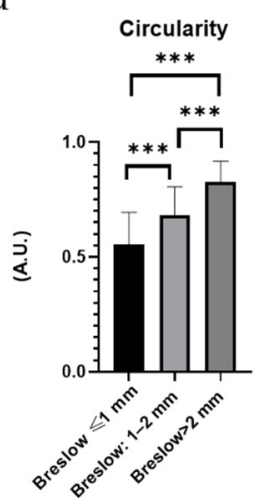

g

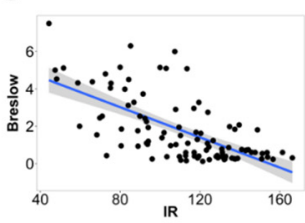

b

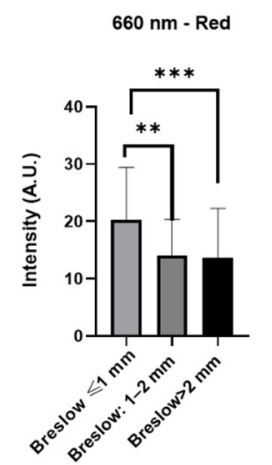

$\mathrm{e}$

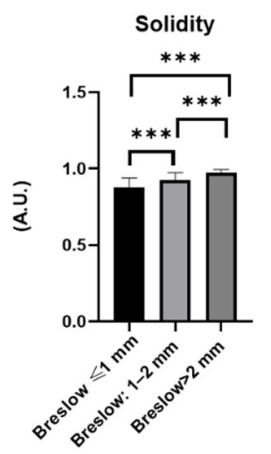

$\mathrm{h}$

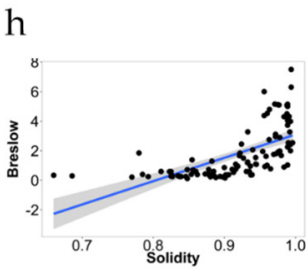

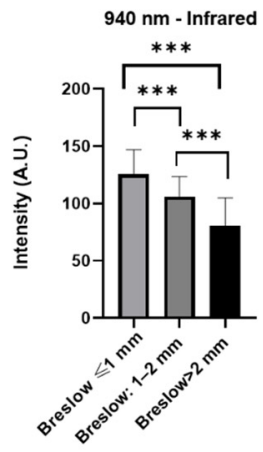

$\mathrm{f}$

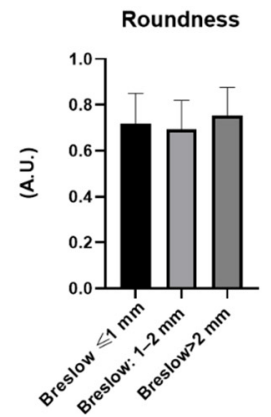

i

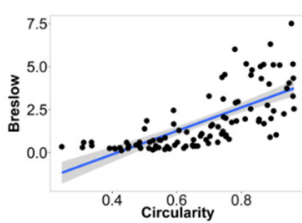

Figure 2. Comparison of melanomas with different tumor thicknesses and correlations between intensity values, shape descriptors, and Breslow thickness. One-way ANOVA and Tukey's post comparison test were used to compare the intensity values and shape descriptors. The intensity values proved to be statistically significant (a) G ( $p<0.0001)$, (b) $\mathrm{R}(p<0.0001)$, and (c) IR $(p<0.0001)$ and among the shape descriptors. (d) Circularity $(p<0.0001)$ and (e) solidity $(p<0.0001)$ were statistically significant. The roundness (f) could not separate the three groups effectively ( $p: 0.2759)$. Moreover, the (G (a), R (b), and IR (c) channels proved to be effective to identify tumors of Breslow $\leq 1 \mathrm{~mm}$ from the other two groups, whereas the IR channel could differentiate the Breslow 1-2 $\mathrm{mm}$ and Breslow $>2 \mathrm{~mm}$ from each other. Pearson's correlation was used to correlate Breslow thickness with IR, circularity, and solidity. It showed a high correlation between IR intensity (g) and Breslow tumor thickness ( $\mathrm{r}:-0.659,95 \%$ confidence interval: -0.7576 to $-0.5317, p$ : $<0.0001$ ), whereas the correlations between Breslow tumor thickness and G or R intensities were low (r: -0.226 and -0.244 , respectively). The correlation was high between solidity and Breslow thickness (h) (r: 0.6324 95\% confidence interval: 0.4978 to $0.7372, p$ : $<0.0001$ ) and high between circularity and Breslow thickness (i) (r: $0.7109,95 \%$ confidence interval: 0.5980 to $0.7961, p$ : <0.0001) $p$ values between 0.01 and 0.001 were considered very significant $(* *)$ and values between 0.001 and 0.0001 were considered extremely significant $\left.{ }^{* * *}\right)$. The results are expressed as mean \pm standard error $(n=100)$. A.U. $=$ arbitrary unit.

\subsection{Differentiation of Nevi from Melanomas with the Use of Parameter s'}

Parameter s' was able to distinguish melanomas from nevi with a sensitivity of $89.60 \%$ and specificity of $88.11 \%$ as the first step of the algorithm. The melanomas had significantly higher parameter s' values compared to the nevi. The ROC AUC analysis showed signifi- 
cant differences also. The comparison of melanoma and nevus groups had an AUC of 0.944 (patients: melanoma, control: nevi, 95\% confidence interval, $p<0.0001$ ) (Figure 3).
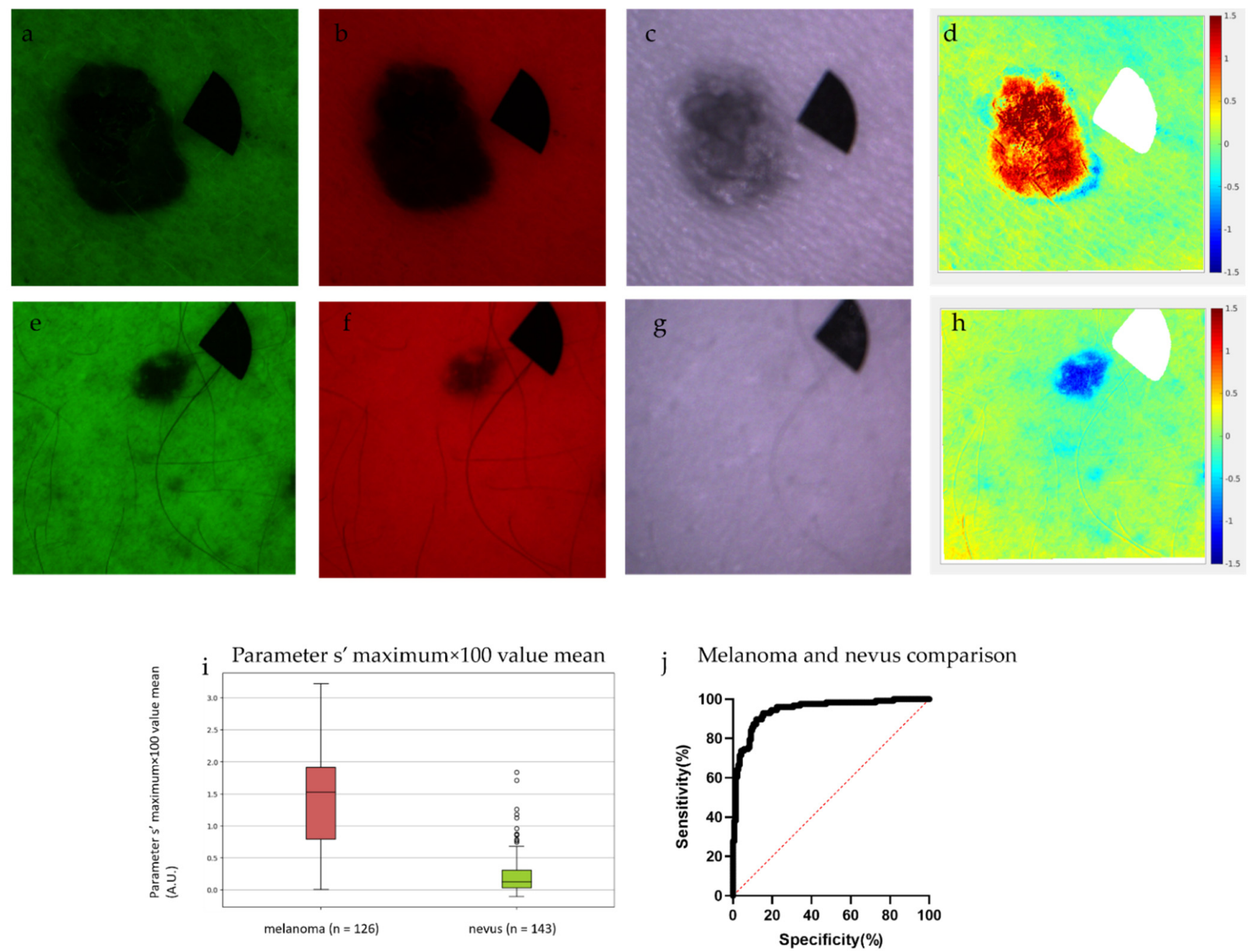

j Melanoma and nevus comparison

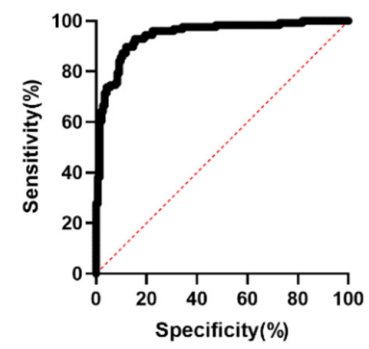

Figure 3. Differentiation of nevi from melanomas with the use of parameter s'. A superficial spreading melanoma, Breslow: 1.02, Clark: IV, pT2a (upper row), and a pigmented nevus (middle row). The parameter maps $(\mathbf{d}, \mathbf{h})$ were calculated using the $G(\mathbf{a}, \mathbf{e}), \mathbf{R}(\mathbf{b}, \mathbf{f})$, and IR (c,g) channels. The melanoma with higher parameter s' is red (d), whereas the nevus with its lower parameter s' is visualized deep blue (h). The redness means higher probability of melanoma (highest parameter $\mathrm{s}^{\prime}$ is 1.5: rufous color), while blueness refers to a higher probability of nevus (lowest parameter s' is -1.5 : deep blue color). Using the maximum values (i) with a threshold of 0.511 arbitrary unit (A.U.) melanomas could be differentiated from nevi with a sensitivity of $89.60 \%$ and specificity $88.11 \%$. The area under the curve (AUC) was 0.944 (patients: melanoma, control: nevi, 95\% confidence interval, $p<0.0001)(\mathbf{j})$. $Y$-axis: sensitivity, $x$-axis: 1 -specificity.

\subsection{Melanoma Classification Algorithm}

We have developed a novel melanoma classification algorithm based on MSI shape descriptors and intensity values that allow us to classify melanomas into the above-mentioned three subgroups with a sensitivity of $78 \%$ and specificity of $89 \%$, (Figure 4 ). The sensitivities for each subgroup were $80.85 \%$ (Breslow $\leq 1 \mathrm{~mm}$ ), 76.19\% (Breslow 1-2 mm), and $81.25 \%$ (Breslow $>2 \mathrm{~mm}$ ). The specificities were $96.22 \%$ (Breslow $\leq 1 \mathrm{~mm}), 82.27 \%$ (Breslow 1-2 mm), and 94.11\% (Breslow $>2 \mathrm{~mm}$ ). The total agreement for predicting the right subgroup was substantial ( $\mathrm{k}=0.67$; 95\% CI, 0.58-0.76), also it was substantial classifying melanomas to Breslow $\leq 1 \mathrm{~mm}$ subgroup ( $\kappa=0.76 ; 95 \% \mathrm{CI}, 0.63$ to 0.89 ) and to Breslow $>2 \mathrm{~mm}$ subgroup ( $\mathrm{k}=0.73 ; 95 \% \mathrm{CI}, 0.59$ to 0.88$)$. The agreement was moderate when the algorithm classified melanomas to the Breslow $1-2 \mathrm{~mm}$ subgroup $(\kappa=0.47$; $95 \%$ CI, 0.28 to 0.65$)$. 


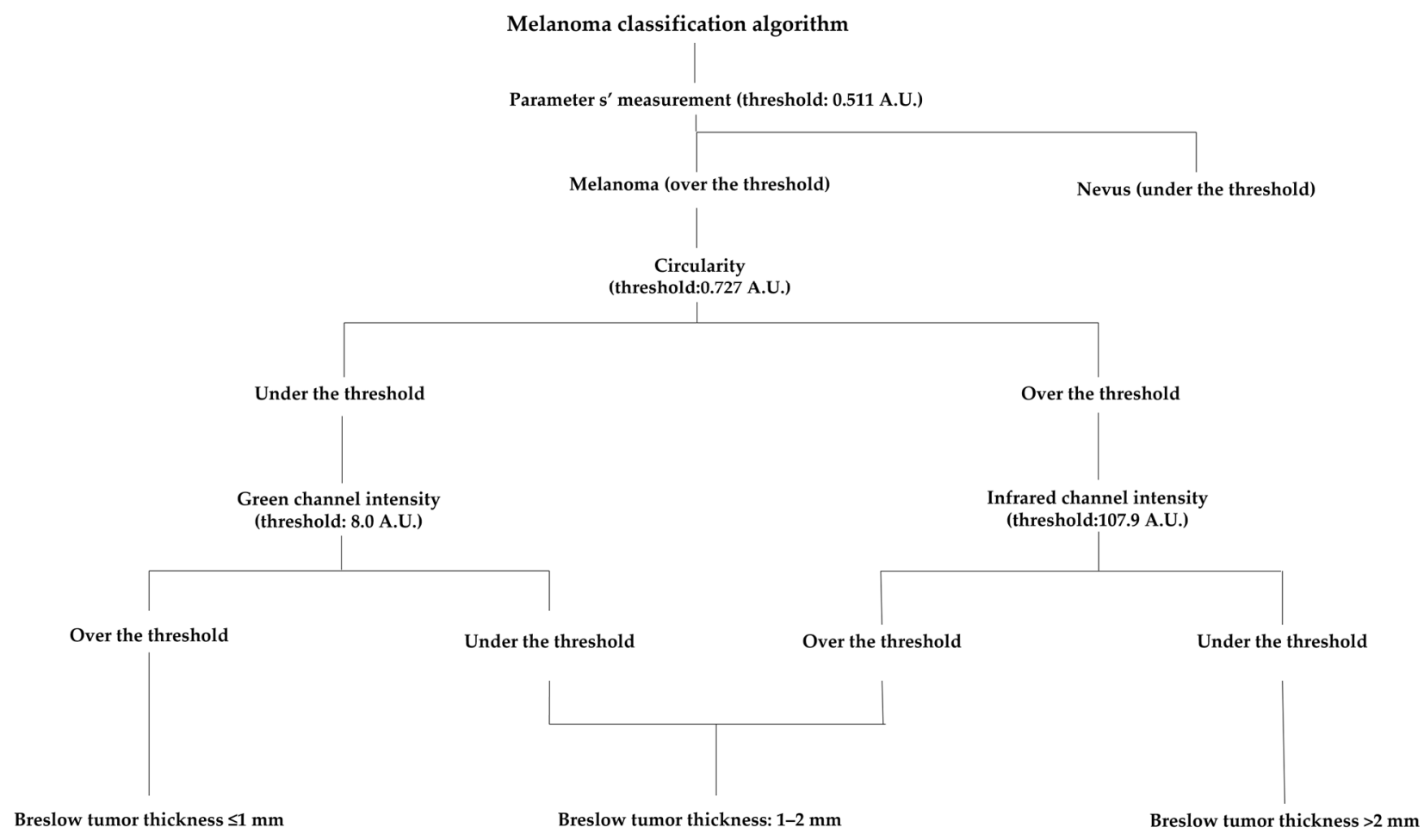

Figure 4. Melanoma classification algorithm. Based on the shape descriptors and intensity values, our melanoma classification algorithm was calculated to classify the multispectral images of melanomas with different Breslow tumor thicknesses. As a first step, this algorithm excludes nevi from the analysis with the use of parameter s' (threshold: 0.511 A.U.). The second step is a threshold between lower and higher circularities that was established (threshold: 0.727 A.U.), which sorted melanomas into two groups: (1) low and (2) high circularity. The third step was the classification of melanomas from these two subgroups to the three previously defined groups (Breslow tumor thickness $\leq 1 \mathrm{~mm}$, Breslow tumor thickness 1-2 mm, Breslow tumor thickness $>2 \mathrm{~mm}$ ). We used the intensity values of green channel (threshold: 8.0 A.U.) and the infrared channel (threshold: 107.9 A.U.). This algorithm was able to classify melanomas into three subgroups with a sensitivity of $78 \%$ and specificity of $89 \%$.

\subsection{Dermoscopic Image Analysis by Dermatologists and Dermatology Residents}

The total sensitivity of their categorization into the three groups described above was $60.38 \%$, while the specificity was $80.86 \%$ with a moderate total agreement $(K=0.41 ; 95 \%$ CI, 0.40 to 0.43 ) (Table 1). The sensitivity of the assessment by dermatologists was $62.19 \%$ with a specificity of $81.09 \%$ and a moderate agreement ( $k=0.44 ; 95 \%$ CI, 0.42 to 0.47 ), whereas the sensitivity of the evaluation by dermatology residents was $58.44 \%$, with a specificity of $79.76 \%$ and a fair agreement $(\kappa=0.39 ; 95 \%$ CI, From 0.36 to 0.41$)$. Among subgroups, classifying into the Breslow $>2 \mathrm{~mm}$ subgroup had the highest total sensitivity of $90.37 \%$ and specificity of $78.58 \%$ with high substantial agreement $(\kappa=0.65 ; 95 \% \mathrm{CI}, 0.61$ to 0.69 ). Classification into the Breslow $\leq 1 \mathrm{~mm}$ subgroup had a sensitivity of $51.69 \%$ and specificity of $96.95 \%$ with a moderate agreement ( $k=0.49 ; 95 \%$ CI, From 0.46 to 0.52 ). The classification into the Breslow 1-2 mm subgroup had a sensitivity of $38.51 \%$ and specificity of $72.07 \%$ with no agreement ( $\mathrm{K}=0.09 ; 95 \% \mathrm{CI}, 0.06$ to 0.13 ). 
Table 1. Comparison of the melanoma classification algorithm and the assessment based on dermoscopic and clinical images by dermatologist and dermatology residents $(n=100)$.

\begin{tabular}{ccc}
\hline & $\begin{array}{c}\text { Melanoma Classification } \\
\text { Algorithm }\end{array}$ & $\begin{array}{c}\text { Assessment Based on Dermoscopic } \\
\text { and Clinical Image }\end{array}$ \\
\hline Cohen's kappa & 0.67 & 0.41 \\
Sensitivity & $78.00 \%$ & $60.38 \%$ \\
Specificity & $89.00 \%$ & $80.86 \%$ \\
\hline
\end{tabular}

\section{Discussion}

MSI allows the examiner to use several wavelength-dependent features and has been previously used to detect melanomas. However, these studies mainly focused on the differentiation of melanomas from other skin lesions [44-49], and only a few studies focused on depth prediction [50]. To the best of our knowledge, we were the first to analyze melanoma tumor thickness with multispectral imaging to classify melanomas into subgroups of great clinical relevance. This was all based on the analysis of their shape descriptors and intensity values. Shape descriptors efficiently differentiated high and low-risk melanomas, namely over $2 \mathrm{~mm}$ vs. less than $1 \mathrm{~mm}$. SMMs are more common among thin melanomas $(p<0.001)$ and NMs are more common among patients with thick melanomas $(p<0.001)$ [51].The combination of shape descriptors and intensity values was sensitive and specific enough for the melanoma classification algorithm to sort melanomas into the three categories, with a sensitivity of $78.00 \%$, specificity of $89.00 \%$ with a substantial agreement $(\kappa=0.67 ; 95 \% \mathrm{CI}, 0.58-0.76)$. Circularity, the sphericity of lesions was the most suitable shape descriptor to classify melanomas into a low- and high-risk group as the second step. Larger and thicker melanomas were more circular. However, circularity alone is not sufficient to accurately establish melanoma thickness, thus a third classification step was needed.

The third analysis step relied on analysis more closely related to the dermal localization of melanoma cells. These findings are in line with our previous findings as shorter wavelengths, such as $G$ and $R$, penetrate the dermis only superficially and are absorbed and reflected by tumor chromophores mainly from the surface [33]. The IR penetrates deeper to the skin and is reflected by tumor chromophores deeper from the dermis [52], consistently with the literature [53]. Therefore, $\mathrm{G}$ channel was suitable to differentiate between Breslow $\leq 1 \mathrm{~mm}$ melanomas and Breslow 1-2 mm melanomas, whereas the IR channel could distinguish between Breslow 1-2 mm melanomas and melanomas with higher than $2 \mathrm{~mm}$ Breslow thickness. Because of its physical characteristics, the $\mathrm{G}$ channel was more useful to identify superficial lesions. Thinner melanomas had higher intensities because of the lower melanin concentration, whereas $G$ channel could not differentiate between Breslow 1-2 $\mathrm{mm}$ and Breslow $>2 \mathrm{~mm}$ melanomas. The IR channel was able to provide information about the deeper layers of the skin. Therefore, it was effective to distinguish better between Breslow 1-2 $\mathrm{mm}$ and Breslow $>2 \mathrm{~mm}$ melanomas. Thinner melanomas are characterized by a higher chance of regression and presence of hypopigmented areas [16], which lesions had higher intensity values in both G and IR channels.

We built in an additional first step into the algorithm to exclude nevi from the analysis using parameter s'. Parameter s' is an improved formula based on our previous findings to differentiate melanoma from nevi [40-43]. It utilizes the intensity values of the lesion and the surrounding skin in $\mathrm{G}$ and $\mathrm{R}$ channels to calculate a predictive value. In our study, melanomas had significantly higher parameter s' values compared to nevi. Therefore, with our thresholding algorithm nevi could be differentiated from melanomas with a sensitivity of $89.60 \%$ and specificity of $88.11 \%$ (Figure 3). These findings are consistent with the literature, where multispectral imaging had been previously applied successfully to differentiate these two entities [45]. Beyond multispectral imaging, melanoma and nevus differentiation is one of the most researched topics in dermatology using various imaging modalities. Many studies have focused on this problem and used computerized and AI-aided methods to differentiate benign lesions from malignant skin tumors [54-57]. 
This is a potentially applicable step to exclude benign pigmented nevi and reconsider the clinical diagnosis when our algorithm is used to estimate tumor thickness of melanoma.

In this study, we also compared the performance of our MSI-based algorithm to that of human observers. Clinical and dermoscopic images of 100 melanomas were shown to dermatologists and dermatology residents to assess their ability to classify the lesion based on tumor thickness. Dermatologists and dermatology residents completed the form with a total sensitivity of $60.38 \%$, of which the dermatologists reached a sensitivity of $62.19 \%$, and the dermatologist residents performed at a sensitivity rate of $58.44 \%$. Specificity reached $80.86 \%$, with $81.09 \%$ and $79.76 \%$ for dermatologists and dermatology residents, respectively. The total agreement was found to be moderate $(K=0.41 ; 95 \% \mathrm{CI}, 0.40$ to 0.43$)$. Compared to the melanoma classification algorithm, all human investigators achieved a lower sensitivity and specificity in classifying melanomas into subgroups based on likely histological tumor thickness. Humans had lower accuracy, and the agreement was higher using the algorithm $(\kappa=0.67 ; 95 \% \mathrm{CI}, 0.58-0.76)$. However, it is important to note that palpation is an important guide to clinicians to aid their vision when estimating the tumor thickness during routine examinations, which was not possible in this study. These data were similar to earlier findings in the literature. Dermoscopy was recently described to predict Breslow tumor thickness with a concordance of 0.52 , and it could even differentiate between in situ melanomas and tumors thicker than $1 \mathrm{~mm}$ [15].

This MSI technique and our novel algorithm is a potential tool to aid clinicians in the evaluation of melanoma depth. It is fast and easy-to-perform, the imaging takes $20 \mathrm{~s}$ whereas running the algorithm needs one minute. It is comparable to other modalities, such as HFUS, which could estimate the required surgical margins of melanomas $(1,2$, or 3 $\mathrm{cm}$ ) in 26 of the 31 subjects [13]. Moreover, preoperative HFUS was found to be a potential tool aid for the excision of melanoma in one step [58]. Combining HFUS with digital dermoscopy enhanced the accuracy also, and could differentiate thick and thin melanomas with a sensitivity of $86.7 \%$ [59]. Optical coherence tomography is a potential tool also to predict melanoma tumor thickness based on their vascular morphology [60]. Reflectance confocal microscopy proved to be an accurate modality in the presurgical margin mapping of only LMMs [61,62]. Although these imaging modalities can be used to estimate Breslow tumor thickness, compared to MSI, their main disadvantage is that they are expensive, and their efficacy depends fundamentally on the examiner's skill and proficiency [63-65].

This multispectral LED-based imaging and our algorithm has several limitations. The field of view of $2 \times 2 \mathrm{~cm}^{2}$ of the device limits the maximum area of the imaging. Another limitation is the acquisition of images of special sites (acral, genital, or mucosal melanoma) is also not possible. The algorithm we created could be potentially further improved in the future. The acquired multispectral images could be applicable as training data for machine learning algorithms. The MSI imaging procedure takes $30 \mathrm{~s}$ and an additional $30 \mathrm{~s}$ is required to upload the images to the cloud server. It takes around one minute to manually carry out the required image analysis for the algorithm and complete the classification. The automatization of this melanoma classifying algorithm is one of our future plans. As a result, the time required for melanoma classification could be further reduced. The last limitation factor is the fact that a multispectral LED device prototype is not widely available yet and it is difficult to compare our results to MSI findings acquired with other imaging settings. The Breslow thickness and its connection with the progression of melanoma is thoroughly investigated in the literature. Thick melanomas show a high risk of early metastasis and locoregional spread [66]. Kulkarni et al. also noted histologic patterns that predict a higher risk of recurrence based on H\&E images processed by deep learning [67]. Breslow thickness and ulceration remain the main predictors of prognosis. Paolino et al analyzed 244 acral melanomas and also noted the importance of these two factors [68]. 


\section{Conclusions}

MSI is a potentially helpful tool to determine the required surgical margin based on the estimated Breslow thickness. It is easy-to-access, cost-effective, and can be used as a mobile add-on device using the camera of a smartphone. The collected data may serve as a training pool for machine learning algorithms for further improvements in order to achieve a more accurate estimation of Breslow thickness, as Marchesini et al. suggested [50].

MSI and dermoscopy are non-invasive imaging modalities. Both can help the specialists estimate melanoma tumor thickness and can aid the differentiation of nevi from melanomas. However, dermoscopy is a tool designed for healthcare professionals with dedicated training $[13,51,69]$. In contrast, MSI requires no previous training and may be used as smartphones attachment to estimate tumor thickness. Based on our findings, MSI may be used in clinical practice for the prediction of appropriate safety margins for curative melanoma excisions.

Author Contributions: Conceptualization: S.B., K.F., N.N.V., A.B., K.L., A.J., N.K., G.P., N.M.W. and E.V.P.; methodology: S.B., K.F., N.N.V., A.J., Á.B., I.L., A.L., N.K. and E.V.P.; software: S.B., N.N.V., K.F., A.J., I.L., A.L. and N.K.; validation: S.B., N.N.V., K.F., Á.B., A.J. and N.K., formal analysis: S.B., N.N.V., K.F., Á.B., A.J., I.L., A.L. and N.K., investigation: S.B., N.N.V., K.F., N.K. and E.V.P., resources: S.B., A.B., K.L., I.L.,A.L., E.K., P.H., M.M., N.K. and N.M.W., data curation: S.B., N.N.V., K.F., A.L., I.L.,Á.B., A.J., E.V.P. and N.K.; writing-original draft preparation: S.B., N.K. and N.M.W. writing-review and editing: S.B., N.N.V., K.F., A.B., K.L., I.L., A.L., E.K., M.M., G.P., P.H., N.K. and N.M.W.; visualization: S.B., Á.B., A.J., E.K. and N.K. supervision, A.L., I.L., A.B., K.L., N.K. and N.M.W. project administration S.B., and N.K.; funding acquisition S.B., N.N.V., A.L., I.L., M.M., N.M.W. and N.K. All authors have read and agreed to the published version of the manuscript.

Funding: This work was supported by grants from the EFOP-3.6.3-VEKOP-16-2017-00009 (S.B., N.N.V.), ÚNKP-21-4-II-SE-10 (N.K.), and ÚNKP-21-2-I-SE-41 (N.N.V.); New National Excellence Program of the Ministry For Innovation and Technology from the source of the National Research, Development and Innovation Fund of Hungary, the National Research, Development and Innovation Office of Hungary-NKFIH (FK_131916, 2019 (Semmelweis University, M.M.)), and the European Regional Development Fund projects "Time-resolved autofluorescence methodology for non-invasive skin cancer diagnostics" (No. 1.1.1.2/16/I/001, agreement No. 1.1.1.2/VIAA/1/16/014 (A.L.)), and European Regional Development Fund project "Development and clinical validation of a novel cost effective multimodal methodology for early diagnostics of skin cancers" (No. 1.1.1.2/16/I/001 agreement No. 1.1.1.2/VIAA/1/16/052 (I.L.)) and the Latvian Council of Science project "Skin cancer early diagnostics accuracy improvement by using neural networks," (No. lzp-2018/2-0052 (I.L., A.L.)).

Institutional Review Board Statement: The study was conducted according to the guidelines of the Declaration of Helsinki and approved by the Institutional Ethics Committee of Semmelweis University (SE RKEB no. 228/2018) and by the Cardiology and Regenerative Medicine Institute (University of Latvia) Scientific Research Ethics Committee on 31 August 2016.

Informed Consent Statement: Informed consent was obtained from all subjects involved in the study.

Data Availability Statement: The data that support the findings of this study are available from the corresponding author N.M.W. upon reasonable request.

Acknowledgments: We thank István Szondy, Natália Czurkó, and Maxime Buitendijk for participating in the measurements as student researchers. We also thank Judit Hársing, Veronika Tóth, József Szakonyi, Daniella Kuzmanovszki, Béla Tóth, Hunor Gergely, Kincső Blága, Dalma Márton, Melinda Fábián, Andor Hodossy- Virágh, Tünde Kerner, Martina Kádas, Dóra Faluhelyi, Cecília Nagy, Sarolta Sándor, and Dénes Póta who took part in the clinical care of the patients. We thank Eleonóra Imrédi, Mariann Müller, Veronika Tóth, Cecília Nagy, Ugur Cakir, Daniella Kuzmanovszki, Pálma Anker, Kincső Blága, Zsófia Tari, Karolina Polgár, József Szakonyi, Isolde Joura, Laura Belvon, and Eszter Müller for helping in the spreadsheet questionnaire. We thank Marta Lange and Bliznuks for the development.

Conflicts of Interest: The authors declare no conflict of interest. 


\section{References}

1. MacKie, R.; Hauschild, A.; Eggermont, A. Epidemiology of invasive cutaneous melanoma. Ann. Oncol. 2009, 20, vi1-vi7. [CrossRef]

2. Garbe, C.; Leiter, U. Melanoma epidemiology and trends. Clin. Dermatol. 2009, 27, 3-9. [CrossRef]

3. Almashali, M.; Ellis, R.; Paragh, G. Melanoma Epidemiology, Staging and Prognostic Factors. In Practical Manual for Dermatologic and Surgical Melanoma Management; Springer: Berlin/Heidelberg, Germany, 2021; pp. 61-81.

4. Schadendorf, D.; van Akkooi, A.C.; Berking, C.; Griewank, K.G.; Gutzmer, R.; Hauschild, A.; Stang, A.; Roesch, A.; Ugurel, S. Melanoma. Lancet 2018, 392, 971-984. [CrossRef]

5. Ward, W.H.; Farma, J.M. Cutaneous Melanoma: Etiology and Therapy; Codon Publications: Brisbane, Australia, $2017 ;$ p. 85.

6. Swetter, S.M.; Tsao, H.; Bichakjian, C.K.; Curiel-Lewandrowski, C.; Elder, D.E.; Gershenwald, J.E.; Guild, V.; Grant-Kels, J.M.; Halpern, A.C.; Johnson, T.M. Guidelines of care for the management of primary cutaneous melanoma. J. Am. Acad. Dermatol. 2019, 80, 208-250. [CrossRef] [PubMed]

7. Sober, A.J.; Chuang, T.-Y.; Duvic, M.; Farmer, E.R.; Grichnik, J.M.; Halpern, A.C.; Ho, V.; Holloway, V.; Hood, A.F.; Johnson, T.M. Guidelines of care for primary cutaneous melanoma. J. Am. Acad. Dermatol. 2001, 45, 579-586. [CrossRef] [PubMed]

8. Sladden, M.J.; Balch, C.; Barzilai, D.A.; Berg, D.; Freiman, A.; Handiside, T.; Hollis, S.; Lens, M.B.; Thompson, J.F. Surgical excision margins for primary cutaneous melanoma. Cochrane Database Syst. Rev. 2009, 3. [CrossRef] [PubMed]

9. Gershenwald, J.E.; Scolyer, R.A.; Hess, K.R.; Sondak, V.K.; Long, G.V.; Ross, M.I.; Lazar, A.J.; Faries, M.B.; Kirkwood, J.M.; McArthur, G.A. Melanoma staging: Evidence-based changes in the American Joint Committee on Cancer eighth edition cancer staging manual. CA Cancer J. Clin. 2017, 67, 472-492. [CrossRef]

10. Coit, D.G.; Andtbacka, R.; Anker, C.J.; Bichakjian, C.K.; Carson, W.E., 3rd; Daud, A.; Dilawari, R.A.; Dimaio, D.; Guild, V.; Halpern, A.C.; et al. Melanoma. J. Natl. Compr. Cancer Netw. 2012, 10, 366-400. [CrossRef]

11. Koshenkov, V.P.; Broucek, J.; Kaufman, H.L. Surgical management of melanoma. In Melanoma; Springer: Cham, Switzerland, 2016; pp. 149-179.

12. Koshenkov, V.P.; Shulkin, D.; Bustami, R.; Chevinsky, A.H.; Whitman, E.D. Role of sentinel lymphadenectomy in thin cutaneous melanomas with positive deep margins on initial biopsy. J. Surg. Oncol. 2012, 106, 363-368. [CrossRef] [PubMed]

13. Polesie, S.; Jergéus, E.; Gillstedt, M.; Ceder, H.; Dahlén Gyllencreutz, J.; Fougelberg, J.; Johansson Backman, E.; Pakka, J.; Zaar, O.; Paoli, J. Can Dermoscopy Be Used to Predict if a Melanoma Is In Situ or Invasive? Dermatol. Pract. Concept. 2021, 11, e2021079. [CrossRef] [PubMed]

14. Rodríguez-Lomba, E.; Lozano-Masdemont, B.; Nieto-Benito, L.M.; Hernández de la Torre, E.; Suárez-Fernández, R.; AvilésIzquierdo, J.A. Dermoscopic Predictors of Tumor Thickness in Cutaneous Melanoma: A Retrospective Analysis of 245 Melanomas. Dermatol. Pract. Concept. 2021, 11, e2021059. [CrossRef] [PubMed]

15. Machet, L.; Belot, V.; Naouri, M.; Boka, M.; Mourtada, Y.; Giraudeau, B.; Laure, B.; Perrinaud, A.; Machet, M.-C.; Vaillant, L. Preoperative measurement of thickness of cutaneous melanoma using high-resolution $20 \mathrm{MHz}$ ultrasound imaging: A monocenter prospective study and systematic review of the literature. Ultrasound Med. Biol. 2009, 35, 1411-1420. [CrossRef] [PubMed]

16. Oh, J.-T.; Li, M.-L.; Zhang, H.F.; Maslov, K.; Wang, L.V. Three-dimensional imaging of skin melanoma in vivo by dual-wavelength photoacoustic microscopy. J. Biomed. Opt. 2006, 11, 034032. [CrossRef] [PubMed]

17. Rajabi-Estarabadi, A.; Bittar, J.M.; Zheng, C.; Nascimento, V.; Camacho, I.; Feun, L.G.; Nasiriavanaki, M.; Kunz, M.; Nouri, K. Optical coherence tomography imaging of melanoma skin cancer. Lasers Med. Sci. 2019, 34, 411-420. [CrossRef] [PubMed]

18. Wang, T.; Mallidi, S.; Qiu, J.; Ma, L.L.; Paranjape, A.S.; Sun, J.; Kuranov, R.V.; Johnston, K.P.; Milner, T.E. Comparison of pulsed photothermal radiometry, optical coherence tomography and ultrasound for melanoma thickness measurement in PDMS tissue phantoms. J. Biophotonics 2011, 4, 335-344. [CrossRef] [PubMed]

19. Stevenson, A.D.; Mickan, S.; Mallett, S.; Ayya, M. Systematic review of diagnostic accuracy of reflectance confocal microscopy for melanoma diagnosis in patients with clinically equivocal skin lesions. Dermatol. Pract. Concept. 2013, 3, 19. [CrossRef]

20. Waddell, A.; Star, P.; Guitera, P. Advances in the use of reflectance confocal microscopy in melanoma. Melanoma Manag. 2018, 5, MMT04. [CrossRef]

21. Kardynal, A.; Olszewska, M.; de Carvalho, N.; Walecka, I.; Pellacani, G.; Rudnicka, L. Reflectance confocal microscopy features of thin versus thick melanomas. G. Ital. Dermatol. Venereol. 2019, 154, 379-385. [CrossRef]

22. Hartmann, D.; Krammer, S.; Ruini, C.; Ruzicka, T.; von Braunmühl, T. Correlation of histological and ex-vivo confocal tumor thickness in malignant melanoma. Lasers Med. Sci. 2016, 31, 921-927. [CrossRef]

23. Jolivot, R.; Benezeth, Y.; Marzani, F. Skin parameter map retrieval from a dedicated multispectral imaging system applied to dermatology/cosmetology. Int. J. Biomed. 2013, 2013, 26. [CrossRef]

24. Zherdeva, L.A.; Bratchenko, I.A.; Myakinin, O.O.; Moryatov, A.A.; Kozlov, S.V.; Zakharov, V.P. In vivo hyperspectral imaging and differentiation of skin cancer. In Proceedings of Optics in Health Care and Biomedical Optics. J. Biomed. Opt. 2016, 10024, 100244G.

25. Kuzmina, I.; Diebele, I.; Spigulis, J.; Valeine, L.; Berzina, A.; Abelite, A. Contact and contactless diffuse reflectance spectroscopy: Potential for recovery monitoring of vascular lesions after intense pulsed light treatment. J. Biomed. Opt. 2011, 16, 040505. [CrossRef] [PubMed]

26. Kuzmina, I.; Diebele, I.; Asare, L.; Kempele, A.; Abelite, A.; Jakovels, D.; Spigulis, J. Multispectral imaging of pigmented and vascular cutaneous malformations: The influence of laser treatment. Laser Appl. Life Sci. 2010, 7376, 73760J. [CrossRef] 
27. Setiadi, I.C.; Nasution, A.M.; Chandra, T.G. A new LED-based multispectral imaging system for blood and melanin content estimation: The validation. AIP Conf. Proc. 2019, 2193, 050017. [CrossRef]

28. Cook, S.E.; Palmer MD, L.C.; Shuler, M.; Franklin, D. Smartphone Mobile Application to Enhance Diagnosis of Skin Cancer: A Guide for the Rural Practitioner. West Va. Med. J. 2015, 111, 22-29.

29. Kuzmina, I.; Lacis, M.; Spigulis, J.; Berzina, A.; Valeine, L. Study of smartphone suitability for mapping of skin chromophores. J. Biomed. Opt. 2015, 20, 090503. [CrossRef] [PubMed]

30. Tamošiūnas, M.; Plorina, E.V.; Lange, M.; Derjabo, A.; Kuzmina, I.; Bliznuks, D.; Spigulis, J. Autofluorescence imaging for recurrence detection in skin cancer postoperative scars. J. Biophotonics 2020, 13, e201900162. [CrossRef]

31. Lange, M.; Bozsányi, S.; Plorina, E.V.; Lihachev, A.; Derjabo, A. Spectral imaging as a tool for the evaluation of skin cancer post-operative scars. Biophotonics 2020, 11585, 1158506. [CrossRef]

32. Lihachev, A.; Lihacova, I.; Plorina, E.V.; Lange, M.; Derjabo, A.; Spigulis, J. Differentiation of seborrheic keratosis from basal cell carcinoma, nevi and melanoma by RGB autofluorescence imaging. Biomed. Opt. Express 2018, 9, 1852-1858. [CrossRef]

33. Bozsányi, S.; Farkas, K.; Bánvölgyi, A.; Lőrincz, K.; Fésûs, L.; Anker, P.; Zakariás, S.; Jobbágy, A.; Lihacova, I.; Lihachev, A. Quantitative Multispectral Imaging Differentiates Melanoma from Seborrheic Keratosis. Diagnostics 2021, 11, 1315. [CrossRef]

34. Farkas, K.; Bozsányi, S.; Plázár, D.; Bánvölgyi, A.; Fésús, L.; Anker, P.; Zakariás, S.; Lihacova, I.; Lihachev, A.; Lange, M. Autofluorescence Imaging of the Skin Is an Objective Non-Invasive Technique for Diagnosing Pseudoxanthoma Elasticum. Diagnostics 2021, 11, 260. [CrossRef]

35. Anker, P.; Fésús, L.; Kiss, N.; Noll, J.; Becker, K.; Kuroli, E.; Mayer, B.; Bozsányi, S.; Lőrincz, K.; Lihacova, I. Visualization of Keratin with Diffuse Reflectance and Autofluorescence Imaging and Nonlinear Optical Microscopy in a Rare Keratinopathic Ichthyosis. Sensors 2021, 21, 1105. [CrossRef] [PubMed]

36. Lihachev, A.; Derjabo, A.; Ferulova, I.; Lange, M.; Lihacova, I.; Spigulis, J. Autofluorescence imaging of basal cell carcinoma by smartphone RGB camera. J. Biomed. Opt. 2015, 20, 120502. [CrossRef]

37. Bliznuks, D.; Jakovels, D.; Saknite, I.; Spigulis, J. Mobile platform for online processing of multimodal skin optical images: Using online Matlab server for processing remission, fluorescence and laser speckle images, obtained by using novel handheld device. In Proceedings of the 2015 International Conference on BioPhotonics (BioPhotonics), Florence, Italy, 20-22 May 2015; pp. 1-4.

38. Spigulis, J. Multispectral, fluorescent and photoplethysmographic imaging for remote skin assessment. Sensors 2017, $17,1165$. [CrossRef] [PubMed]

39. Abràmoff, M.D.; Magalhães, P.J.; Ram, S.J. Image processing with ImageJ. Biophotonics Int. 2004, 11, 36-42.

40. Diebele, I.; Kuzmina, I.; Lihachev, A.; Kapostinsh, J.; Derjabo, A.; Valeine, L.; Spigulis, J. Clinical evaluation of melanomas and common nevi by spectral imaging. Biomed. Opt. Express 2012, 3, 467-472. [CrossRef] [PubMed]

41. Lihacova, I.; Bolochko, K.; Plorina, E.V.; Lange, M.; Lihachev, A.; Bliznuks, D.; Derjabo, A. A method for skin malformation classification by combining multispectral and skin autofluorescence imaging. Biophotonics Photonic Solut. Better Health Care VI 2018, 10685, 1068535

42. Lihacova, I.; Bolocko, K.; Lihachev, A. Semi-automated non-invasive diagnostics method for melanoma differentiation from nevi and pigmented basal cell carcinomas. Biophotonics_Riga 2017, 10592, 1059206.

43. Lange, M.; Kiss, N.; Fesus, L.; Plorina, E.V.; Derjabo, A.; Spigulis, J. Non-invasive LED-based screening solution for skin cancer. In Proceedings of the European Conference on Biomedical Optics, Munich, Germany, 23-25 June 2019; p. 11073 _17.

44. Tomatis, S.; Carrara, M.; Bono, A.; Bartoli, C.; Lualdi, M.; Tragni, G.; Colombo, A.; Marchesini, R. Automated melanoma detection with a novel multispectral imaging system: Results of a prospective study. Phys. Med. Biol. 2005, 50, 1675. [CrossRef]

45. Elbaum, M.; Kopf, A.W.; Rabinovitz, H.S.; Langley, R.G.; Kamino, H.; Mihm, M.C., Jr.; Sober, A.J.; Peck, G.L.; Bogdan, A.; Gutkowicz-Krusin, D. Automatic differentiation of melanoma from melanocytic nevi with multispectral digital dermoscopy: A feasibility study. J. Am. Acad. Dermatol. 2001, 44, 207-218. [CrossRef]

46. Carrara, M.; Bono, A.; Bartoli, C.; Colombo, A.; Lualdi, M.; Moglia, D.; Santoro, N.; Tolomio, E.; Tomatis, S.; Tragni, G Multispectral imaging and artificial neural network: Mimicking the management decision of the clinician facing pigmented skin lesions. Phys. Med. Biol. 2007, 52, 2599. [CrossRef] [PubMed]

47. Diebele, I.; Kuzmina, I.; Kapostinsh, J.; Derjabo, A.; Spigulis, J. Melanoma-nevus differentiation by multispectral imaging. In Proceedings of the European Conference on Biomedical Optics, Munich, Germany, 22-26 May 2011; p. 80872G. [CrossRef]

48. Diebele, I.; Bekina, A.; Derjabo, A.; Kapostinsh, J.; Kuzmina, I.; Spigulis, J. Analysis of skin basalioma and melanoma by multispectral imaging. Biophotonics Photonic Solut. Better Health Care III 2012, 8427, 842732. [CrossRef]

49. Kuzmina, I.; Diebele, I.; Jakovels, D.; Spigulis, J.; Valeine, L.; Kapostinsh, J.; Berzina, A. Towards noncontact skin melanoma selection by multispectral imaging analysis. J. Biomed. Opt. 2011, 16, 060502. [CrossRef] [PubMed]

50. Marchesini, R.; Bono, A.; Tomatis, S.; Bartoli, C.; Colombo, A.; Lualdi, M.; Carrara, M. In vivo evaluation of melanoma thickness by multispectral imaging and an artificial neural network. A retrospective study on 250 cases of cutaneous melanoma. Tumori J. 2007, 93, 170-177. [CrossRef]

51. Martínez-Piva, M.; Vacas, A.; Kowalczuk, M.R.; Gallo, F.; Vasconcelos, M.R.; Mazzuoccolo, L. Dermoscopy as a Tool for Estimating Breslow Thickness in Melanoma. Actas Dermosifiliogr. 2021, 112, 434-440. [CrossRef]

52. Lange, M.; Plorina, E.V.; Lihacova, I.; Derjabo, A.; Spigulis, J. Skin cancer screening-better safe than sorry. SHS Web Conf. 2020, 85, 02003. [CrossRef] 
53. Ly, E.; Cardot-Leccia, N.; Ortonne, J.P.; Benchetrit, M.; Michiels, J.F.; Manfait, M.; Piot, O. Histopathological characterization of primary cutaneous melanoma using infrared microimaging: A proof-of-concept study. Br. J. Dermatol. 2010, 162, 1316-1323. [CrossRef]

54. Esteva, A.; Kuprel, B.; Novoa, R.A.; Ko, J.; Swetter, S.M.; Blau, H.M.; Thrun, S. Dermatologist-level classification of skin cancer with deep neural networks. Nature 2017, 542, 115-118. [CrossRef] [PubMed]

55. Rastgoo, M.; Garcia, R.; Morel, O.; Marzani, F. Automatic differentiation of melanoma from dysplastic nevi. Comput. Med. Imaging Graph. 2015, 43, 44-52. [CrossRef]

56. Wells, A.; Patel, S.; Lee, J.B.; Motaparthi, K. Artificial intelligence in dermatopathology: Diagnosis, education, and research. J. Cutan. Pathol. 2021, 48, 1061-1068. [CrossRef]

57. Maron, R.C.; Haggenmüller, S.; von Kalle, C.; Utikal, J.S.; Meier, F.; Gellrich, F.F.; Hauschild, A.; French, L.E.; Schlaak, M.; Ghoreschi, K. Robustness of convolutional neural networks in recognition of pigmented skin lesions. Eur. J. Cancer 2021, 145, 81-91. [CrossRef]

58. Chaput, L.; Laurent, E.; Pare, A.; Sallot, A.; Mourtada, Y.; Ossant, F.; Vaillant, L.; Patat, F.; Machet, L. One-step surgical removal of cutaneous melanoma with surgical margins based on preoperative ultrasound measurement of the thickness of the melanoma. Eur. J. Dermatol. 2018, 28, 202-208. [CrossRef]

59. Pellacani, G.; Seidenari, S. Preoperative melanoma thickness determination by 20-MHz sonography and digital videomicroscopy in combination. Arch. Dermatol. 2003, 139, 293-298. [CrossRef] [PubMed]

60. De Carvalho, N.; Welzel, J.; Schuh, S.; Themstrup, L.; Ulrich, M.; Jemec, G.B.; Holmes, J.; Kaleci, S.; Chester, J.; Bigi, L. The vascular morphology of melanoma is related to Breslow index: An in vivo study with dynamic optical coherence tomography. Exp. Dermatol. 2018, 27, 1280-1286. [CrossRef]

61. Chen, C.S.; Elias, M.; Busam, K.; Rajadhyaksha, M.; Marghoob, A. Multimodal in vivo optical imaging, including confocal microscopy, facilitates presurgical margin mapping for clinically complex lentigo maligna melanoma. Br. J. Dermatol. 2005, 153, 1031-1036. [CrossRef] [PubMed]

62. Yélamos, O.; Cordova, M.; Blank, N.; Kose, K.; Dusza, S.W.; Lee, E.; Rajadhyaksha, M.; Nehal, K.S.; Rossi, A.M. Correlation of handheld reflectance confocal microscopy with radial video mosaicing for margin mapping of lentigo maligna and lentigo maligna melanoma. JAMA Dermatol. 2017, 153, 1278-1284. [CrossRef] [PubMed]

63. Wolner, Z.J.; Yélamos, O.; Liopyris, K.; Rogers, T.; Marchetti, M.A.; Marghoob, A.A. Enhancing skin cancer diagnosis with dermoscopy. Dermatol. Clin. 2017, 35, 417-437. [CrossRef]

64. Levine, A.; Markowitz, O. Introduction to reflectance confocal microscopy and its use in clinical practice. JAAD Case Rep. 2018, 4, 1014-1023. [CrossRef]

65. Schneider, S.L.; Kohli, I.; Hamzavi, I.H.; Council, M.L.; Rossi, A.M.; Ozog, D.M. Emerging imaging technologies in dermatology: Part II: Applications and limitations. J. Am. Acad. Dermatol. 2019, 80, 1121-1131. [CrossRef]

66. Stucky, C.-C.H.; Gray, R.J.; Dueck, A.C.; Wasif, N.; Laman, S.D.; Sekulic, A.; Pockaj, B.A. Risk factors associated with local and in-transit recurrence of cutaneous melanoma. Am. J. Surg. 2010, 200, 770-775. [CrossRef]

67. Kulkarni, P.M.; Robinson, E.J.; Pradhan, J.S.; Gartrell-Corrado, R.D.; Rohr, B.R.; Trager, M.H.; Geskin, L.J.; Kluger, H.M.; Wong, P.F.; Acs, B. Deep learning based on standard H\&E images of primary melanoma tumors identifies patients at risk for visceral recurrence and death. Clin. Cancer Res. 2020, 26, 1126-1134. [PubMed]

68. Paolino, G.; Bekkenk, M.; Didona, D.; Eibenschutz, L.; Richetta, A.; Cantisani, C.; Viti, G.; Carbone, A.; Buccini, P.; De Simone, P. Is the prognosis and course of acral melanoma related to site-specific clinicopathological features? Eur. Rev. Med. Pharmacol. Sci. 2016, 20, 842-848.

69. Lallas, A.; Longo, C.; Manfredini, M.; Benati, E.; Babino, G.; Chinazzo, C.; Apalla, Z.; Papageorgiou, C.; Moscarella, E.; Kyrgidis, A. Accuracy of dermoscopic criteria for the diagnosis of melanoma in situ. JAMA Dermatol. 2018, 154, 414-419. [CrossRef] [PubMed] 